\title{
Australian physician advises advance planning for final exit
}

Published at www.cmaj.ca on Nov. 4

I n many ways, it felt like a typical church gathering, although it was a suicide workshop. The elderly crowd of about 50 exchanged hushed pleasantries while they settled into their seats at the First Unitarian Congregation of Toronto in Ontario on Oct. 13. A kindly, graying woman with her hair in a bun poured coffee and tea.

Dr. Philip Nitschke addressed the audience in near-sermon fashion. "It's actually not too easy to end your life," he told the congregants. "Plan ahead."

Most appeared eager for advice. "We're just here to fine tune our exit strategy," said a 78-year-old man who had been diagnosed with prostate cancer and had a suicide pact with his wife.

Kathy Fowler, 60, travelled with her brother from a small Ontario town to hear Nitschke speak. She had witnessed her father's suffering from lung cancer and a variety of other ailments and when he attempted to kill himself, "we, as a family, were sad he wasn't successful," Fowler explains.

Nitschke, the founder of the Australian-based, pro-euthanasia organization Exit International, ran through the litany of ideal ways of killing oneself - hypothetically, of course, because aiding, abetting, or counselling a person to suicide is a crime in Canada punishable with a jail sentence of up to 14 years.

One could swallow pentobarbital, a hardy barbiturate that can be bought over the counter at most veterinary clinics in Mexico. The drug has a lengthy shelf life, allowing one to prepare years ahead, said Nitschke. "Once you have the recourse to a peaceful death in your cupboard, you stop worrying."

Alternatively, one could tighten a helium or nitrogen-filled plastic bag around one's neck, a method, Nitschke assured the wincing crowd, that does not feel at all like suffocation. Or one could travel to Switzerland, the only country in the world where euthanasia

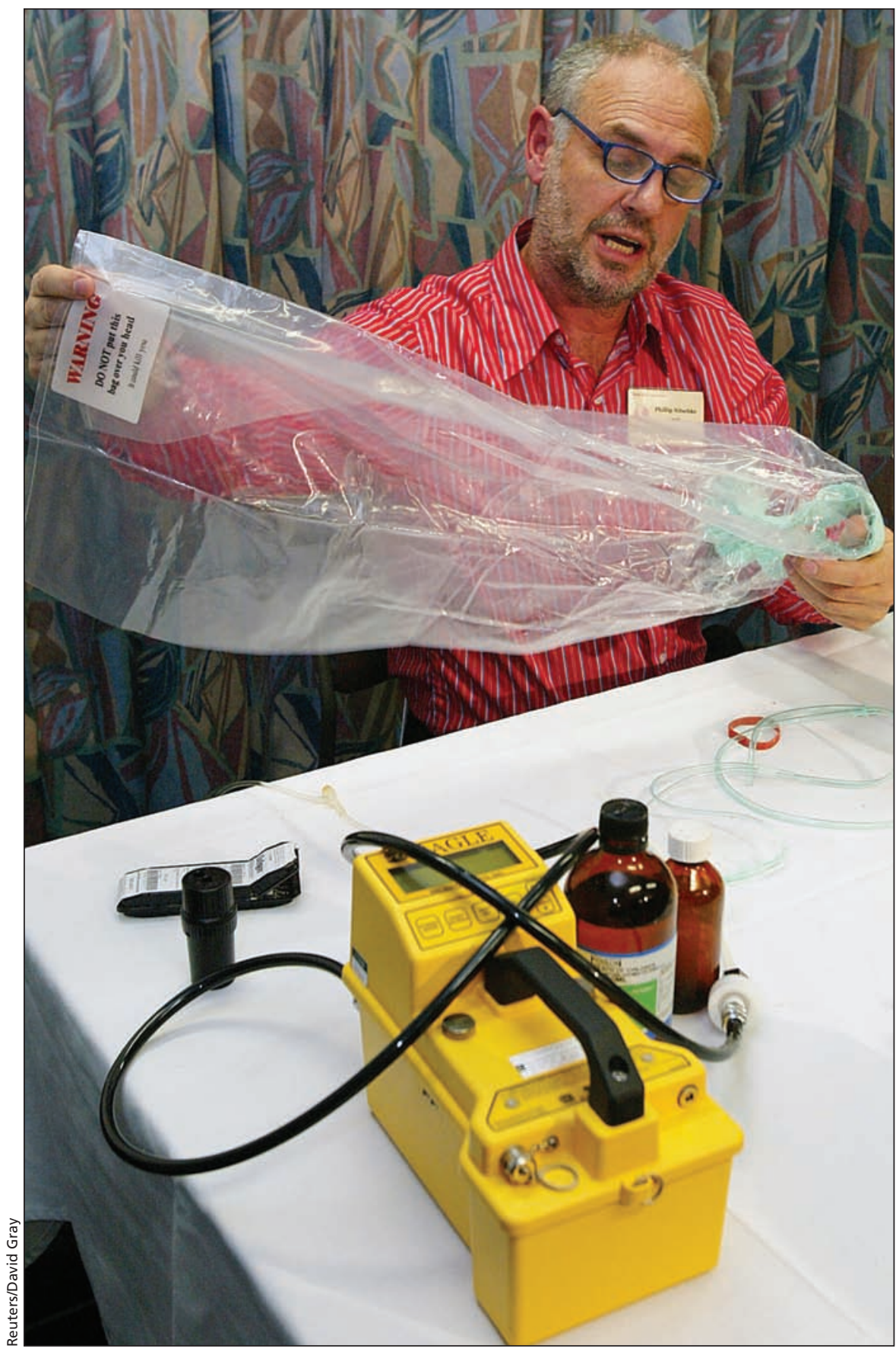

Australian euthanasia campaigner Dr. Philip Nitschke holds one of his "Aussie Bags," which suffocates its user by closing gently and automatically around their neck, typically after the user first takes a sleeping pill.

is administered to foreigners. As a last alternative, a small number of pharmaceuticals - including chloroquine and insulin - would do in a pinch, though they're "not as good as Nembutal," Nitschke informed the audience. 
Nitschke's organization contends that any adult of sound mind who wishes to end his or her life should have access to safe means of doing so and that euthanasia legislation would be helpful.

But he also argued that a medical condition shouldn't be a necessary condition, citing the case of Lisette Nigot, an Australian woman who decided to end her life when she was 80 , simply because she'd "had enough" (as documented in the film, The Madmoiselle and the Doctor). "The more I tried to push her that this was not a good idea, the more she said, 'Go away, don't patronize me," "he said, explaining that he ultimately concluded he had no right to push Nigot one way or the other.

Not surprisingly, Nitschke has been harshly attacked by politicians, ethicists and the religious community. His book, The Peaceful Pill, is banned in Australia. His office is frequently raided by authorities and in September, the Television Bureau of Canada banned an advertising campaign for Exit International. Prominent ethicist Margaret Somerville has charged that the organization's arguments "threaten the legal and moral landscape" of Canada.

Nitschke said censure has also come from the medical profession. "[Doctors] don't hand over the keys to this natural process easily."

Nitschke indicated in a later interview that he first began to think about assisted suicide in the early 1990s, when an Australian province, the Northern Territory, proposed to make euthanasia an option for the terminally ill.

"I thought: 'That's a good idea'," he says.

The following day, an Australian Medical Association representative was in the news claiming that "there isn't a doctor in the Northern Territory that would support this," Nitschke adds.

In response to what he saw as "insufferable paternalism," Nitschke took out a full-page advertisement listing 20 physicians and surgeons who supported the legislation. But when the first candidate, a man suffering stomach cancer, drove $3000 \mathrm{~km}$ to a hospital to be reviewed by a panel of doctors, Nitschke couldn't find a doctor willing to break Australian Medical Association ranks by sitting on the panel.

"The College of Physicians and Surgeons rang me and said, 'You have your law but it isn't going to work." Nitschke was the first doctor to deliver a voluntary lethal injection in Australia but the law was repealed after eight months.
Although $67 \%$ of Canadians and $85 \%$ of Australians support legal euthanasia, according to polls conducted by Angus Reid in Canada and by the Northern Territory News in Australia, Nitschke says support from the medical community is lower than the general population. "Some people think you can either support palliative care or euthanasia. They don't think you can have both."

After the public meeting in the church, Nitschke provided more detailed advice in private to those who paid around $\$ 60$ and had signed a legal disclaimer. The session included demonstration videos and allowed for those who had questions about the legality and safety of their own suicide plans to ask Nitschke for candid advice, participants said.

By helping people work out "effective" suicide options that wouldn't criminally implicate others, Nitschke argues that he is being more humane than antieuthanasia advocates. "The most common way for elderly people in Canada to kill themselves is by hanging or gunshot," he says. "The laws drive people down desperate paths." Wendy Glauser, Toronto, Ont.

DOI:10.1503/cmaj.109-3710 